International Journal of Instruction e-ISSN: 1308-1470 • www.e-iji.net

Article submission code: 20201018152147

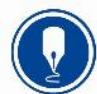

October $2021 \bullet$ Vol.14, No.4

p-ISSN: 1694-609X

pp. $223-240$

Received: 18/10/2020

Revision: 06/03/2021
Accepted: 30/03/2021

OnlineFirst: 17/07/2021

\title{
Distinctive Features of Executive Functions among Students with Differing Levels of Probabilistic Thinking Style
}

\author{
Alexander Viktorovich Dobrin \\ Bunin Yelets State University, Russia, alexander.v.dobrin@yandex.ru
}

Sergey Victorovich Shcherbatykh

Prof., Bunin Yelets State University, Russia, scherbatych2017@yandex.ru

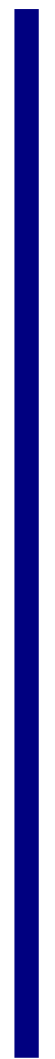

This study aims to study the control of interference and self-control in students with different levels of probabilistic thinking style (PTS). The study covered 90 students (average age $20 \pm 3.03$ years). The sample subjects were formed through the approximate modeling method. The experimental group covered students from the 1 st to the 4 th year. At the first stage, the features of the probabilistic thinking style were studied. At the second stage, the features of brake control were analyzed. The features of the probabilistic thinking style were studied through such methods as R. Amthauer's Test, New Uncertainty Tolerance Questionnaire (NTQ), S. Epstein's Intuitive Style Questionnaire, and the Prediction Ability Test (L.A. Regush). O.M. Razumnikova studied peculiarities of the interference control using the "Interference" method, the features of self-control using the ReBOS method. The results showed that students with a high level of PTS effectively use probabilistic knowledge and skills to make the right decision. Students demonstrate the ability to identify patterns and essence of probabilistic phenomena effectively using mental operations such as analysis, synthesis, generalization, comparison, and classification. It was found that the better the processes of inhibitory control are formed, the more efficiently the process of correlating the conditions of the problem and the information that can be used to solve it is carried out, and the more efficient the subject can identify common signs and properties of objects or concepts, compare them, move from visual-effective forms of comparison with the abstract comparison, that is, the higher the level of development of probabilistic thinking style. The revealed features of inhibitory processes and working memory in students, depending on the level of development of the probabilistic thinking style, make it possible to predict the effectiveness of student decision-making in a situation of uncertainty, and thus to develop effective strategies for finding innovative ways, methods, and means of enhancing the cognitive, including the mental activity of students.

Keywords: probabilistic thinking style, behavioral control, sensory-motor integration, working memory interference, self-control, students

Citation: Dobrin, A. V., \& Shcherbatykh, S. V. (2021). Distinctive features of executive functions among students with differing levels of probabilistic thinking style. International Journal of Instruction, 14(4), 223-240. https://doi.org/10.29333/iji.2021.14414a 


\section{INTRODUCTION}

There are situations when automated actions do not correspond to changing tasks, and automatic — instinctive — behavior becomes ineffective or impossible. In such situations, the regulation of behavior is carried out using a set of descending mental processes necessary for concentration, defined as "executive functions," which, in Russian terminology, means "behavioral change management" (Burgess \& Simons, 2005; Bari \& Robbins, 2013). In turn, one of the central mechanisms for controlling behavioral change is inhibitory control (Lehto et al., 2003).

It is known that inhibitory control includes interferential control and self-control (Theeuwes, 2010). Interferential control suppresses dominant mental representations, i.e. carries out cognitive suppression, which includes resistance to unwanted memories/thoughts (Anderson \& Levy, 2009); resistance to proactive interference from information received previously; resistance to proactive interference from data received later; intentional forgetting. Cognitive suppression usually correlates with the working memory indicators, suppressing thoughts that are undesirable for solving a problem.

Self-control is an aspect of inhibitory control that includes control over both behavior and emotions. Another aspect of self-control is self-discipline (Muraven, 2010). It is a known fact that the inhibition of involuntary attention and the suppression of involuntary action is closely related to one another (Kray \& Ferdinand, 2014). It has been shown that if a task requires the use of self-control and the second type of self-control is immediately offered in a different area, then the execution of the second task is worse than in a situation where the execution occurred without a preliminary task (Munakata $e t$ al., 2011).

An analysis of the prognostic significance of behavioral change management functions is particularly relevant, as today we know that children with well-formed inhibitory processes perform better in school and are more attentive (Paul, 2012).

In turn, when stereotyped behavior that automatically repeats a certain sequence of actions is ineffective, probabilistic thinking plays a key role in making an adequate decision (Chigirinskaya, 2017). We know that probabilistic thinking style (PTS) allows us to make adequate decisions in conditions, where there is little information and time and space are limited. The decision-making process itself is based on the knowledge of the nature of these random processes, the features of their course, and the probabilistic assessment of events (Chigirinskaya, 2017).

Teplov first introduced the concept of probabilistic thinking into domestic psychological science. According to him, the structure of this way of thinking includes assertions about the probability of expected events (Teplov, 1961). Further studies of this thinking style showed that probabilistic forecasting is done with PTS (Feigenberg, 1986) based on the use of mathematics, with the aim of a probabilistic description of events and phenomena of the surrounding world (Nalimov, 1960). This is consistent with modern research, which speaks of the important role of mathematical abilities, which allow creating a variety of representations, and on their basis, facilitate the search for alternative solutions to problems (Kusumah, Kustiawati, Herman, 2020). 
An analysis of the probabilistic thinking style shows the many ways that it can be understood. These include understanding the world through the construction of probabilistic mental models (Collins \& Michalski, 1989; Gigerenzer et al., 1991; Johnson-Laird, 1994); a way of thinking that allows us to draw probabilistic conclusions based on the methods of deduction and induction (Johnson-Laird, 1994); the ability to interpret and critically evaluate probabilistic information and random phenomena (Gal, 2005); thinking based on causal relationships of a statistical nature with various probabilistic generalizations (Ponomaryov \& Shapovalenko, 2008); an individual thinking system, such as the strategy of probabilistic-statistical description, and an understanding of the laws of reality (Dvoryatkina, 2013); or a cognitive activity that contains the element of uncertainty (Sari \& Hermanto, 2017). Therefore, the probabilistic thinking style is currently defined as a unique system of methods that are used for identifying and formulating uncertain and problematic situations and then searching for a solution. It includes the following abilities: the ability to differentiate chance and causality; to predict the possibilities of its development based on a combination of intuition, deduction, and induction, while also considering the random nature of the constituent elements and their relationship; and to make the right decision in situations with high degrees of uncertainty, a variety of choices, alternatives, and opportunities.

Speaking about the components of the probabilistic thinking style, it should be noted that at present there is no single understanding of its structure.

Johnson-Laird (1994) sees "mental models" that correspond to an infinite set of possibilities (or, in some cases, a finite set of infinite sets of possibilities) acting as structural components of probabilistic thinking.

Batanero and Borovcnik (2016) describe the structural components of probabilistic thinking are: theoretical probability; conditional probability, which is based on their dependence on previous judgments, as well as the asymmetry of probabilities associated with causality; reasoning based on probabilistic data.

A study by Pfannkuch et al. (2016) shows that the building blocks of probabilistic thinking are knowledge of the context of the event and knowledge of the probability of the occurrence of an event. They form a "meta-image", defined as a spatial picture, internal or external, which is the basis for constructing the process of probabilistic thinking. Next, the mental picture of the imaging system is built. The next step is the actualization of the ability to see the structure in their problem situations, and then there is a comparison with the elements of the simulated probability, and as a result, a probabilistic model of thinking is built and the problem situation is solved. In their work, the authors identify a mechanism for the implementation of probabilistic thinking, which is launched based on a problem situation. As soon as a problem situation is identified, motivational arousal arises, which provides the process of modeling probabilistic thinking. The next step is to propose options for solving a problem situation, and then the stochastic model for solving a problem situation is built. At the last stage, the selected model is tested and, if positive, the model is used as the basis for solving a problem situation (Pfannkuch et al., 2016). 
Mooney et al. (2014) proposed the structure of probabilistic thinking, which includes structural probabilistic thinking, non-structural probabilistic thinking, multi-structure probabilistic thinking, and relational probabilistic thinking.

Polyakova (2006) identifies the logical, combinatorial, and probabilistic-statistical components of the probabilistic thinking style, and Dvoryatkina (2013) includes logical and intuitive components to probabilistic thinking.

In our study, in addition to the logical, intuitive, combinatorial, and probabilisticstatistical components, we also highlight the prognostic component in the structure of the PTS, which is based on the success of orientation in the flow of sensory signals ensured by the plasticity of the nervous system and which plays a key role in the learning process (Nikolaeva \& Vergunov, 2013).

It is obvious that students with a high level of probabilistic thinking style operate more effectively with representations created based on logic and intuition, assess their probability, and as a result, quickly make the most correct decision in difficult situations of choice and uncertainty, that is, in situations in which one of the main mechanisms for managing behavior change is inhibitory control.

Thus, on the one hand, many studies reveal the significance of the functions of managing behavior change in the decision-making process, in situations where stereotypical, automated actions do not correspond to the changed tasks, and on the other hand, there is a lot of data indicating that in such situations in the decision-making process an adequate solution, one of the key roles is played by the probabilistic thinking style.

However, there are not enough data on the PTS development level in students with different formation levels of inhibitory processes.

Thus, the problem of the relationship between psychophysiological mechanisms of behavior control and the peculiarities of thinking in the decision-making process is one of the most relevant today, which determined the purpose of this study - to study the peculiarities of Executive Functions in students with different levels of probabilistic thinking style, as well as to identify the features of the relationship between data parameters.

Analysis of works devoted to the probabilistic thinking style, as well as its components, allowed us to assume that the higher the PTS level, the more efficiently students make decisions in a situation of uncertainty, and, therefore, the mechanisms of inhibitory control in these students are more effective.

\section{METHOD}

\section{Research design}

An experimental study covering bachelor students enrolled in different courses and areas of study at the university was conducted. The subjects were offered methods to 
identify the features of the probabilistic thinking style, as well as the peculiarities of inhibitory control.

Students were examined individually using all experimental methods. Constant external conditions of the experiment were observed. Since the diagnostic block took a lot of time, the student could not complete all the methods on one experimental day. The subjects passed R. Amthauer's test on one experimental day. The next day, diagnostics were carried out according to the following methods: New Uncertainty Tolerance Questionnaire (NTQ), S. Epstein's Intuitive Style Questionnaire, and the Prediction Ability Test. The subject was presented with verbal instructions for each method. Data for each student was recorded in the prepared protocols for each method.

Also, on some days, methods were carried out aimed at identifying the features of the inhibitory processes of the subjects.

The examination was carried out in the morning in the same room, without the presence of strangers, while maintaining a clear sequence of presentation of the methods.

\section{Sample}

To identify the features of the peculiarities of interference control and self-control in students with different levels of probabilistic thinking style, 90 students were examined (average age $20 \pm 3.03$ years). The formation of the sample of subjects was carried out using the method of approximate modeling in compliance with the criteria of operational validity, internal and external validity. The experimental group covered students from the 1 st to the 4th year. Both male and female students were selected equally from each course.

At the first stage, the features of the probabilistic thinking style were studied. At the second stage, the features of brake control were analyzed.

All methods used in the study have a known, proven level of reliability, validity, and accuracy.

\section{Instrument and Procedures}

To study the features of the probabilistic thinking style, we used such methods as the Amthauer's Test of Intelligence (2003), the New Uncertainty Tolerance Questionnaire (Kornilova, 2010), Epstein's Intuitive Style Questionnaire (Stepanosova et al., 2004), and the Ability to Predict Test (Regush, 2003). The features of the interferential control were studied using Razumnikova's "Interference" method (Razumnikova \& Savinykh, 2016), and the features of self-control were studied using the ReBOS method (Nikolaeva \& Vergunov, 2013).

R. Amthauer's test consists of 9 subtests of 16-20 tasks each. Description of tasks and sample solutions are given in the instructions placed before each subtest. The tasks of any subtest should be done within a strictly defined time, for which the subject needs to find solutions to the submitted tasks. 
The test offers 176 tasks to the examinee. The total examination time (without preparatory procedures and instructing the subjects) is 90 minutes. All answers were recorded on special sheets (forms), which indicated the subject's pseudonym, as well as the date and time of the start of work. When calculating "raw" marks (except for the IV subtest), each correct solution is estimated at 1 point. Then the results were interpreted according to the commentary to the method.

When creating the test, Amthauer (2003) proceeded from the concept that intelligence is a specialized substructure in the holistic structure of the personality and is closely connected with other components of the personality, such as volitional and emotional spheres, interests, and needs.

Amthauer's test (2003) includes the following subtests:

"SP - Supplement of proposals" - the subtest determines the stock of relatively simple information and knowledge from various fields. This subtest performs a motivational function.

"WE - Word Exclusion" - the subtest is designed to study the analytical and synthetic activity of the subjects. The data obtained from it allows for judging the ability of subjects to distinguish common signs and properties of objects or concepts, their ability to compare, move from clearly effective forms of comparison to abstract comparison.

"An - Analogy" - the solution to this type of problem involves a high level of development of the generalization operation and determines the level of development of verbal and logical thinking.

"Gn - Generalization" - this subtest diagnoses the level of development of the abstraction operation.

"AT - Arithmetic tasks" - the implementation of the tasks of this subtest allows for identifying the subject's ability to mathematical analysis and synthesis, logical inference, mathematical generalization.

"NS - Number series" - solving the problems of this subtest allows for identifying the level of development of the comparison operation, and, consequently, the analytical and synthetic activity.

"SI - Spatial Imagination" - this subtest allows for determining the level of development of spatial thinking.

"SG - Spatial Generalization" - the implementation of the tasks of this subtest allows for identifying the level of development of visual-effective thinking.

"MA - Memory, Mnemonic Abilities" - according to the results of completing the tasks of this subtest, one can judge the level of development of short-term memory.

Thus, Amthauer's test (2003) reveals the features of the logical, combinatorial, and probabilistic-statistical components of the probabilistic thinking style. 
S. Epstein's intuitive style questionnaire allows for evaluating how highly a person's awareness of the willingness to rely on intuition.

In the process of diagnostics, the subject was presented with a questionnaire form consisting of 20 items, with which the respondent must express the degree of his agreement on a 5-point Likert scale. Items are grouped into 2 scales that do not have common items. Some of the points are interpreted in reverse meanings. The interpretation of the results was carried out per the commentary to the methodology.

S. Epstein means a steady preference to rely on the process of solving various problems and performing various actions on intuitive cognition by intuitive cognitive style. $S$. Epstein's questionnaire includes rationality and intuitive style scales. The last scale is set by two subscales - an intuitive ability, which diagnoses the subject's tendency to rely on intuition when making decisions, and using intuition, which allows for identifying the subject's ideas about their ability to form accurate premonitions.

The New Uncertainty Tolerance Questionnaire (NTQ) (Kornilova, 2010) is a Russianlanguage integrated methodology designed to measure such personality characteristics as uncertainty tolerance.

In the process of diagnostics, the subject was presented with a questionnaire form, on which the subject had to note the degree of his agreement or disagreement with the above statements. The processing of the results consisted of a simple summation of the points scored. In this case, each answer is assigned from 1 to 7 points ("completely disagree" - 1 point, "completely agree" - 7 points). The interpretation of the results was carried out per the commentary to the methodology.

Tolerance has been interpreted as an integral personality characteristic studied in the following main ways: psychological stability, a system of personal and group values, personality attitudes, and collections of different levels of individual properties.

A new uncertainty tolerance questionnaire, constructed because of testing the total questionnaire of Furnham (1994). It allows for quantifying the scales of "Tolerance to Uncertainty" (TU), "Intolerance to Uncertainty" (IU), and "Interpersonal Intolerance to Uncertainty" (IIU) as the adoption of uncertainty in interpersonal relationships. Today it is the most reliable questionnaire for measuring TU and IU in Russian-language samples (Kornilova \& Chumakova, 2014).

TU should be understood as a generalized personality trait, which means a desire for change, novelty, and originality, a willingness to go the wrong way and prefer more complex tasks, can be independent, and go beyond the accepted limits. IU focuses on the desire for clarity, orderliness in everything and the rejection of uncertainty, the assumption of the predominant role of rules and principles, the dichotomous separation of right and wrong ways, opinions, and values. IIU is well interpreted as an interpersonal IU, i.e. means the desire for clarity and control in interpersonal relationships, discomfort in the event of uncertainty in relations with others. In general, this meets the criteria of instability, monologicity, and static in relations with others. 
To study the features of forecasting, the "Forecasting ability" test was selected by Regush (2003), consisting of 20 pairs of stimulus statements, some of which are camouflage ones. The theoretical basis for creating this test was the factor model (Regush, 2003) of the structure of the ability to predict. The author considers forecasting as cognitive ability, which includes "the totality of the cognitive processes of the subject, which determines the success of forecasting in any activity, including prognostic" (Regush, 2003). In the structure of prognostic abilities of a personality, Regush (2003) identifies two levels of their development: cognitive and personal. The basis of the cognitive level is the speech-cognitive component, represented by such qualities of thinking as analyticity, awareness, flexibility, perspectives, and evidence. Test tasks are aimed at identifying these qualities. An integral indicator of the method is the level of ability to predict.

In the process of diagnostics, the subject is asked to read each of the statements, and in the form for answers, opposite the statement corresponding to the point of view of the subject, put "+", and opposite the statement that does not correspond to the point of view "-". After receiving answers to the questionnaire, the points are calculated. The answers are compared with the key described in the methodology. If the subject's answers coincide with the key's answer, he is assigned 1 point, in case of mismatch - 0 points. Then all points are summed up. The interpretation of the results was carried out per the commentary to the methodology.

The study of the features of braking control included the study of the features of interference control using the "Interference" method by Razumnikova (Razumnikova \& Savinykh, 2016), and the features of self-control using the ReBOS method (Nikolaeva \& Vergunov, 2013).

The "Interference" method allows us to evaluate the degree of interference in the working memory. The method consists of three episodes, and each of them sequentially presents 30 items. Each time, the test subject is asked to select a new item that was not previously selected. A repeated selection of an item concludes the first episode. In the second episode, the test subject is shown the same incentives but in a different order. A repeated selection, yet again, concludes the episode and starts the third one, in which incentives are, too, shown in a different order. The method estimates the number of memorized objects, as well as the interference of the working memory - the difference in the number of reproduced objects in each series.

The ReBOS method allows for evaluating the features of sensorimotor integration within the framework of a simple and complex sensorimotor reaction, which demonstrates the quality of prediction of the fractal structure of the sensor flow. In the process of evaluating a simple sensorimotor reaction, the subject was asked to respond with the same type of action (in our case, press the Spacebar) for each stimulus presented. Evaluation of a complex sensorimotor reaction involved responding with the same type of action to all stimuli, except for one chosen by the experimenter (in our experiment, the subject had to press the Spacebar when all stimuli except the red circle appeared). In this case, the rate of development of the inhibitory response, the ability of 
the nervous system to be flexible when interacting with the external environment is assessed (Nikolaeva \& Vergunov, 2013).

\section{Statistical Processing}

Several statistical methods were used to answer the research questions.

In particular, the Mann-Whitney U-test was used to test the assumption that the mean values of the two populations from which the compared samples were extracted differ from each other.

The relationship of one variable (dependent) and another or several other variables (independent) were studied using regression analysis.

The data obtained are summarized using Microsoft Excel.

Statistical data analysis was performed using the IBM SPSS Statistics software (version 22).

\section{FINDINGS AND DISCUSSION}

At the first stage, we analyzed the distribution of subjects by the level of PTS development. It was revealed that students are characterized by an average PTS level of $56 \%$ (Table 1).

Table 1

The level of the probabilistic thinking style development among students, \%

\begin{tabular}{lll}
\hline Low & Average & High \\
\hline 18 & 56 & 26 \\
\hline
\end{tabular}

The analysis of the individual components of the probabilistic thinking style among students showed that subjects with a high level of PTS development (26\%) are characterized by a high level of development of their ability to use probabilistic knowledge and skills to make the right decision. Such students show the ability to effectively identify patterns and essences of probabilistic phenomena through mental operations, such as analysis, synthesis, generalization, comparison, and classification; they demonstrate the ability to determine, contemplate or consider all possible combinations of various signs, events, or phenomena in the process of solving the task; in a situation of uncertainty, they demonstrate the ability to successfully navigate it, as well as the ability to operate with probabilistic representations based on the statistical data analysis. The students exhibit a high level of intuitive cognitive style, they tend to trust intuition and can use it when solving various tasks; they can easily accept the situation of uncertainty, which allows them to find the optimal solution in limited conditions; they exhibit a high level of forecasting ability.

Students with an average level of PTS development (56\%) are less capable to use probabilistic knowledge and skills in the decision-making process. These students can identify patterns of probabilistic phenomena using mental operations, but they make the right decision only when it is obvious. When making a decision, they can determine combinations of various signs, however, they do it superficially and take into account 
only the most obvious and significant signs, events, or phenomena. In situations of uncertainty, such students demonstrate an average level of ability to use probabilisticstatistical information. They do not show a tendency to trust intuition or to use it, their prediction ability is average. This is manifested in an insufficiently effective process of constructing a situation model in the process of searching for new methods and means of solution.

Students with a low level of PTS development (18\%) consider only obvious combinations of various signs, events, or phenomena, which does not always help effectively to solve a problem. Such students cannot effectively navigate a situation of uncertainty and use probabilistic representations. This makes it difficult for them to find an adequate solution in limited conditions. In the decision-making process, they rarely use intuition and do not trust it when they do. Besides, such students have difficulties accepting uncertain situations and are highly intolerant to uncertainty in general. At the same time, these students exhibit an average level of forecasting ability. At the second stage, we analyzed the volume of working memory among students with different levels of PTS (Table 2).

Table 2

The volume of students' working memory (mean value and standard deviation)

\begin{tabular}{lllll}
\hline \multirow{2}{*}{ Parameters } & \multicolumn{3}{l}{ Level of PTS development } \\
\cline { 2 - 4 } & Low & Average & High \\
\hline Interference index P(in) & $3.8 \pm 10.6$ & $5.38 \pm 9.0$ & $-1.67 \pm 7.6$ \\
\hline $\begin{array}{l}\text { The sum of memorized incentives in three } \\
\text { episodes of presentation P(sum) }\end{array}$ & $30.8 \pm 6.8$ & $38.5 \pm 12.9 \boldsymbol{\Delta}$ & $32.1 \pm 10.6$ \\
\hline \multirow{2}{*}{$\begin{array}{l}\text { Number of memorized } \\
\text { objects }\end{array}$} & 1st try & $12.8 \pm 6.4$ & $17.4 \pm 6.4 \backsim \bullet \boldsymbol{\Delta}$ & $10.5 \pm 6.1$ \\
\cline { 2 - 4 } & 2nd try & $9.2 \pm 5.3$ & $9.0 \pm 5.4$ & $9.5 \pm 5.6$ \\
\cline { 2 - 5 } & 3rd try & $8.8 \pm 6.0$ & $12.0 \pm 6.1$ & $12.1 \pm 6.1$ \\
\hline
\end{tabular}

Note: $\boldsymbol{\Delta}$ is the difference between subjects with low and average levels with the significance level of $p \leq 0,05$ (the Mann-Whitney $U$ ); $\boldsymbol{\square}$ is the difference between the number of memorized objects in the 1 st and 2 nd episodes at the significance level of $\mathrm{p} \leq 0,05$; $\bullet$ is the difference between the number of memorized objects in the 1 st and 2 nd tries at the significance level of $\mathrm{p} \leq 0,05$.

The results of the analysis show that there are no significant differences between students with differing levels of PTS. However, it should be noted that the results of the students with low and average PTS levels tend to deteriorate. This is confirmed by significant differences in the number of reproductions in the first, second, and third episodes of the students with an average PTS level. A negative value of the P(in) in the results of the students with a high level of PTS indicates a gradual improvement in reproduction.

When analyzing each episode individually, some differences in the number of memorized objects were observed. Students with an average level of PTS development have significantly more reproduced objects in the first attempt than students with both low and high levels of PTS. However, the reproduction of the students with low and average PTS levels tends to deteriorate after each try. On the contrary, students with a 
high level of PTS showed an improvement in reproduction with each try, which indicates a decrease in working memory interference (Bunge et al., 2002).

The data obtained are consistent with the results of studies, which show that the lower the interference of working memory, the more the subject uses random data, phenomena, and events in the decision-making process (Grégoire et al., 2012; Nikolaeva, Sutormina, 2019), that is, the higher is level of probabilistic thinking style.

The third stage of the research included an analysis of the time needed for producing simple and complex sensory-motor reactions (Table 3).

Table 3

The reaction time of the students with different levels of PTS (mean value and standard deviation)

\begin{tabular}{llll}
\hline \multirow{2}{*}{ Parameter } & \multicolumn{3}{l}{ Level of PTS development } \\
\cline { 2 - 4 } & Low & Average & High \\
\hline The first part of a simple reaction & $303.7 \pm 44.7$ & $318.1 \pm 56.1$ & $287.2 \pm 16.6$ \\
\hline The second part of a simple reaction & $314.1 \pm 39.6$ & $318.7 \pm 83.5$ & $296.5 \pm 19.2$ \\
\hline The first part of a complex reaction & $369.4 \pm 36.9$ & $363.6 \pm 48.1$ & $361.4 \pm 16.7$ \\
\hline The second part of a complex reaction & $377.6 \pm 36.3$ & $389.1 \pm 61.4 *$ & $376.1 \pm 37.4$ \\
\hline
\end{tabular}

Note: $*$ is the difference in time between the first and second parts of a complex reaction with the significance level of $\mathrm{p} \leq 0,05$ (the Mann-Whitney $\mathrm{U}$ ).

The table shows that the second part of a complex sensory-motor reaction takes more time than the first part for the group of students with an average level of PTS. The same tendency can be observed for the other two groups, but the differences in their case do not reach the level of significance. An analysis of the number of incentive omissions in a simple sensory-motor reaction was carried out during the fourth stage of the study (Table 4).

Table 4

The number of incentive omissions in a simple sensory-motor reaction (mean value and standard deviation)

\begin{tabular}{lll}
\hline $\begin{array}{l}\text { PTS } \\
\text { level }\end{array}$ & $\begin{array}{l}\text { The number of incentive omissions in } \\
\text { the 1st part of a simple sensory-motor } \\
\text { reaction }\end{array}$ & $\begin{array}{l}\text { The number of incentive omissions in } \\
\text { the 2nd part of a simple sensory-motor } \\
\text { reaction }\end{array}$ \\
\hline Low & $5.1 \pm 10.6$ & $5.2 \pm 11.1$ \\
\hline Average & $2.6 \pm 5.6$ & $2.8 \pm 4.8$ \\
\hline High & $1.0 \pm 1.5$ & $1.8 \pm 2.1 *$
\end{tabular}

Note: $*$ is a difference in the number of omissions at the significance level of $\mathrm{p} \leq 0,05$ (the Mann-Whitney U).

It has been revealed that the number of incentive omissions in the second part of a simple sensory-motor reaction is higher than in the first part for the students with a high level of PTS. Although the number of omissions does not differ very much between all groups of subjects, we can observe its reduction with an increase in the level of PTS. The smallest number of omissions is typical for students with a high level of probabilistic thinking and the largest for students with a low level. 
The obtained data are consistent with the results of studies, which show that the features of the test for determining the parameters of sensorimotor integration are associated with decision-making mechanisms in situations of uncertainty (Nikolaeva, Vergunov, 2017; Luna et. al 2015).

The features of inhibitory processes were analyzed in the fifth stage of the research (Table 5).

Table 5

Inhibitory processes' features (mean value and standard deviation)

\begin{tabular}{llll}
\hline \multirow{2}{*}{ Parameter } & \multicolumn{3}{l}{ PTS component } \\
\cline { 2 - 4 } & \multicolumn{3}{l}{1} \\
\cline { 2 - 4 } & \multicolumn{3}{l}{ Prognostic component } \\
\hline The first part of a complex reaction & $349.2 \pm 35.2$ & $355.1 \pm 33.8$ & $399.4 \pm 32.2^{*}$ \\
\hline The second part of a complex reaction & $365.3 \pm 39.1$ & $370.3 \pm 36.5$ & $431.1 \pm 18.5^{*}$ \\
\hline dH of a complex reaction & $0.4 \pm 0.5$ & $0.3 \pm 0.4$ & $1.0 \pm 0.1^{*}$ \\
\hline
\end{tabular}

Note: ${ }^{*}$ is the difference between the students' reaction-time with the significance level of $p \leq 0,05$ (the Mann-Whitney U).

The results show that the features of inhibitory processes among students with different levels of PTS components vary. The largest value of a reaction-time is typical for students with a high level of the prognostic component. The same group of students also exhibits the largest value of the $\mathrm{dH}$ parameter that indicates the accuracy with which the subject reproduces the fractal dimension of the incentives' sequence. The $\mathrm{dH}$ parameter for these students was high in the first and second parts of a complex reaction.

These data are consistent with studies that show that the decision-making mechanism in a situation of a probabilistic outcome of events is associated with the features of inhibitory control (Nikolaeva, Vergunov, 2017; Razumnikova, 2019)

The next step was to analyze the characteristics of the relationship between the components of a probabilistic thinking style and the characteristics of a simple and complex sensorimotor reaction (Table 6). 
Table 6

The relationship between simple and complex sensorimotor reactions and components of the probabilistic style of students' thinking

\begin{tabular}{|c|c|c|c|c|}
\hline Independent variable & Dependent variable & $\mathrm{R}$ & $\mathrm{R} 2$ & $\mathrm{P}$ \\
\hline $\begin{array}{l}\text { The number of omissions in the first } \\
\text { part of a simple sensorimotor reaction }\end{array}$ & $\begin{array}{l}\text { "Logical component } \\
\text { of PTS" }\end{array}$ & 0.441 & 0.241 & 0.003 \\
\hline $\begin{array}{l}\text { The number of omissions in the first } \\
\text { part of a complex sensorimotor reaction }\end{array}$ & $\begin{array}{l}\text { "Logical component } \\
\text { of PTS" }\end{array}$ & 0.371 & 0.137 & 0.028 \\
\hline $\begin{array}{l}\text { The number of omissions in the second } \\
\text { part of a complex sensorimotor reaction }\end{array}$ & $\begin{array}{l}\text { "Logical component } \\
\text { of PTS" }\end{array}$ & 0.403 & 0.162 & 0.021 \\
\hline $\begin{array}{l}\text { The number of errors in the second part } \\
\text { of a complex sensorimotor reaction }\end{array}$ & $\begin{array}{l}\text { Intuitive component } \\
\text { of PTS }\end{array}$ & 0.371 & 0.138 & 0.028 \\
\hline \multirow{2}{*}{ Interference indicator I(in) } & $\begin{array}{l}\text { "Logical component } \\
\text { of PTS" }\end{array}$ & 0.339 & 0.115 & 0.043 \\
\hline & $\begin{array}{l}\text { Intuitive component } \\
\text { of PTS }\end{array}$ & 0.368 & 0.149 & 0.020 \\
\hline "dH" of complex sensorimotor reaction & $\begin{array}{l}\text { Predictor component } \\
\text { of PTS }\end{array}$ & 0.577 & 0.333 & 0.019 \\
\hline $\begin{array}{l}\text { The number of remembered objects } \\
\text { Attempt \#3 }\end{array}$ & $\begin{array}{l}\text { Intuitive component } \\
\text { of PTS }\end{array}$ & 0.408 & 0.167 & 0.013 \\
\hline
\end{tabular}

Note: $\mathrm{R}$ is the coefficient of determination; $\mathrm{R} 2$ is the percentage of the variance of the dependent variable, explained by the change in the independent variable; $p$ is the significance level.

The results obtained using regression analysis indicate that the variable "Number of omissions in the first part of a simple sensorimotor reaction" is associated with such a dependent variable as the "Logical component of PTS". It was established that the independent variable "Number of omissions in the second part of a simple sensorimotor reaction" is also associated with such a dependent variable as the "Logical component of PTS". Therefore, the features of the analysis and synthesis process that require solving the problem (SP subtest), as well as the features of analytical and synthetic activity (WE and NS subtests) are associated with the number of omissions, both in the first and in the second part simple sensorimotor reaction.

An analysis of the relationship between the number of omissions in a complex sensorimotor reaction and the components of a probabilistic thinking style showed that these parameters are also related. Thus, the number of omissions in the first and second parts of a complex sensorimotor reaction correlates with the level of development of the logical component of a probabilistic thinking style. The analysis of the regression coefficient of the revealed relationship showed that the higher the level of development of the logical component of PTS, the more errors the subject makes.

The results are explained by the fact that subjects with a high level of probabilistic thinking style can successfully detect some stable and repeating pattern (the results of a simple sensorimotor reaction). However, the speed of generating an inhibitory response and, therefore, missing the forbidden signal (in this case, a red circle) is insufficient for 
them, as evidenced by the increase in errors when performing a complex sensorimotor reaction in students with a high level of PTS (positive correlation coefficient of the parameters "Number of errors in the second part of a complex sensorimotor reaction" and "Intuitive component of PTS").

A study of the accuracy of the distribution of the fractal dimension of the stimulus sequence in a simple and complex sensorimotor reaction ( $\mathrm{dH}$ parameter) showed that accuracy in the process of performing a complex sensorimotor reaction is associated with the prognostic component of the probabilistic thinking style.

The obtained results indicate that the better the subject when performing the sensorimotor reaction procedure during the 2 nd part of the series, reproduced the fractal dimension of the stimulus stream, the higher his predictive ability indicators.

An analysis of the relationship between the indicators of working memory interference showed that this parameter (I(in)) is associated with an intuitive component of the probabilistic thinking style. An analysis of the correlation coefficient showed that the higher the level of PTS development, the lower the index of interference of working memory in students. This is also evidenced by the positive correlation between the number of memorized objects in attempt No. 3 and the level of development of the intuitive component of PTS.

The obtained results show that the more effective the mechanisms of inhibitory control are, the higher the level of probabilistic thinking style is.

A high level of probabilistic thinking style is typical for subjects who exhibit a higher efficiency of inhibitory processes that ensure the completion of obsolete behavioral forms, as well as higher efficiency of working memory, which provides memorization of individual stages of a behavioral act until its completion (Nikolaeva \& Vergunov, 2017).

In turn, the effective use of random and rare information in the decision-making process is ensured by the interference of working memory (Nikolaeva \& Sutormina, 2019). The interference slows down the reproduction of information, and the higher it is, the less the subject uses random data in the decision-making process and is more oriented by frequently repeating phenomena and events (Grégoire et al., 2012; Nikolaeva \& Sutormina, 2019).

The data obtained show that the students with a high level of PTS have the lowest levels of working memory interference $(-1.67 \pm 7.6)$ in contrast to students with low $(3.8 \pm$ 10.6) and average $(5.38 \pm 9.0)$ levels, which indicates a more efficient use of random information, as well as the use of all possible combinations of various signs, events or phenomena in the process of solving a problem.

Thus, the better such mechanisms for managing behavior change as interference control and self-control are formed, the more efficiently the process of correlating the condition of the problem and the information that can be used to solve it is carried out, and the more efficiently the student can identify common features and properties of objects or concepts. , to compare them, to move from visual-effective forms of comparison to an 
abstract comparison, that is, the higher his level of development of the probabilistic thinking style.

\section{CONCLUSION AND SUGGESTION}

The analysis of the results of the study showed that students are characterized by an average level of development of the probabilistic thinking style $(56 \%)$. The higher the level of probabilistic thinking style, the lower the interference of working memory. The time to complete the sensorimotor reaction is higher in students with a high level of the prognostic component of PTS.

Therefore, the more effective the student's inhibitory processes and working memory are, the more effectively he/she makes decisions in situations of uncertainty when the decision-making process itself is based on the knowledge of the nature and characteristics of random processes and the probabilistic assessment of events.

This study has several limitations. In particular, it should be noted that our data were obtained on a sample of 90 subjects. In this regard, it is necessary to increase the sample of subjects in the next study to be sure that the data can be extended to a larger number of subjects.

This data was also obtained on a sample whose age was $20 \pm 3.03$ years, which does not allow for interpreting the results at an earlier age of the subjects, and several research methods do not apply to younger subjects, which does not allow this study to be carried out at the initial stage learning at school.

The authors see the prospects for further study of the problem in a more detailed study of the features of probabilistic thinking, both among students and schoolchildren at various stages of education.

In the authors' opinion, it would be interesting to study the features of the probabilistic thinking style in primary and secondary school students with a tough level of formation of inhibitory control, since the analysis of the behavior change management functions in childhood is of great prognostic value, which is proved by many longitudinal and nonlongitudinal studies.

\section{ACKNOWLEDGEMENT}

The study was funded by RFBR according to the research project No. 18-313-20002.

\section{REFERENCES}

Amthauer, R. (2003). Amthauer's test of intelligence. Practical course on personality psychology.

Anderson, M., \& Levy, B. (2009). Suppressing unwanted memories. Current Directions in Psychological Science, 18, 189-194. https://doi.org/10.1111/j.14678721.2009.01634.x 
Bari, A., \& Robbins, T. W. (2013). Inhibition and impulsivity: Behavioral and neural basis of response control. Progress in Neurobiology, 108, 44-79. https://doi.org/10.1016/j.pneurobio.2013.06.005

Batanero, C., \& Borovcnik, M. (2016). Statistics and probability in high school. Sense Publishers. https://doi.org/10.1007/978-94-6300-624-8

Bunge, S. A., Dudukovic, N. M., Thomason, M. E., Vaidya, C. J., \& Gabrieli, J. D. (2002). Immature frontal lobe contributions to cognitive control in children: evidence from fMRI. Neuron, 33, 301-311. https://doi.org/10.1016/S0896-6273(01)00583-9

Burgess, P., \& Simons, J. (2005). Theories of frontal lobe executive function: Clinical applications. In P. W. Halligan \& D. T. Wade (Eds.), The effectiveness of rehabilitation for cognitive deficits (pp. 211-231). Oxford University Press. https://doi.org/10.1093/acprof:oso/9780198526544.003.0018

Chigirinskaya, N. V. (2017). Coherent and stochastic learning objectives - The means for the development of the stochastic culture of technical university students: General design principles. Modern Problems of Science and Education, 1. https://scienceeducation.ru/en/article/view?id=26139

Collins, A. M., \& Michalski, R. (1989). The logic of plausible reasoning: A core theory. Cognitive Science, 13, 1-49. https://doi.org/10.1207/s15516709cog1301_1

Dvoryatkina, S. N. (2013). The development of a probabilistic thinking style in the process of teaching mathematics: Theory and practice. INFRA-M.

Feigenberg, I. M. (1986). To see, to foresee, to act. Knowledge.

Furnham, A. (1994). A content, correlational, and factor analytic study of four tolerance of ambiguity questionnaires. Personality and Individual Differences, 16(3), 403-410. https://doi.org/10.1016/0191-8869(94)90066-3

Gal, I. (2005). Towards "probability literacy" for all citizens: building blocks and instructional dilemmas. In G. Jones (Ed.), Exploring probability in schools: challenges for teaching and learning (pp. 39-63). Springer.

Gigerenzer, G. G., Hoffragc, U., \& Kleinbolting, H. (1991). Probabilistic mental models: A Brunswikian theory of confidence. Psychological Review, 8, 506-528. https://doi.org/10.1037//0033-295X.98.4.506

Grégoire, S., Rivalan, M., Le Moine, C., \& Dellu-Hagedorn, F. (2012). The synergy of working memory and inhibitory control: Behavioral, pharmacological, and neural functional evidence. Neurobiology of Learning and Memory, 97, 202-212. https://doi.org/10.1016/j.nlm.2011.12.003

Johnson-Laird, P. N. (1994). Mental models and probabilistic thinking. Cognition, 50, 189-209. https://doi.org/10.1016/0010-0277(94)90028-0

Kornilova, T. V. (2010). The new uncertainty tolerance questionnaire. Psychological Journal, 31(1), 74-86. 
Kornilova, T. V., \& Chumakova, M. A. (2014). Tolerance and intolerance of ambiguity in the modification of Budner's questionnaire. Experimental Psychology (Russia), 7(1), 92-110. https://psyjournals.ru/files/68181/exp_2014_n1_Kornilova.pdf

Kray, J., \& Ferdinand, N. K. (2014). Task switching and aging. In J. A. Grange \& G. Houghton (Eds.), Task switching and cognitive control (pp. 350-371). Oxford University Press. https://doi.org/10.1093/acprof:osobl/9780199921959.003.0014

Kusumah, Y. S., Kustiawati, D., \& Herman, T. (2020). The Effect of GeoGebra in ThreeDimensional Geometry Learning on Students' Mathematical Communication Ability. International Journal of Instruction, 13(2), 895-908. https://doi.org/10.29333/iji.2020.13260a

Lehto, J., Juuja“rvi, P., Kooistra, L., \& Pulkkinen, L. (2003). Dimensions of executive functioning: Evidence from children. British Journal of Developmental Psychology, 21, 59-80. https://doi.org/10.1348/026151003321164627

Luna, B., Marek, S., Larsen, B., Tervo-Clemmens, B., \& Chahal, R. (2015). An integrative model of the maturation of cognitive control. Annual Review of Neuroscience, 38, 151-170. https://doi.org/10.1146/annurev-neuro-071714-034054

Mooney, E. S., Langrall, C. W., \& Hertel, J. T. (2014). A practical perspective on probabilistic thinking models and frameworks. In E. J. Chernof \& B. Sriraman (Eds.), Probabilistic thinking (pp. 495-507). Springer.

Munakata, Y., Herd, S. A., Chatham, C. H., Depue, B. E., Banich, M. T., \& O’Reilly, R. C. (2011). A unified framework for inhibitory control. Trends in Cognitive Sciences, 15, 453-459. https://doi.org/10.1016/j.tics.2011.07.011

Muraven, M. (2010). Building self-control strength: Practicing self-control leads to improved self-control performance. Journal of Experimental Social Psychology, 46(2), 465-468. https://doi.org/10.1016/j.jesp.2009.12.011

Nalimov, V. V. (1960). The use of mathematical statistics in the analysis of the matter. Physical and Mathematical Literature State Publishing House.

Nikolaeva, E. I., \& Sutormina, N. V. (2019). The relationships between the parameters of sensorimotor integration with the size and interference in working memory in children of 5-6 years. Modern Problems of Science and Education, 4. https://scienceeducation.ru/en/article/view?id=29099

Nikolaeva, E. I., \& Vergunov, E. G. (2013). Forecast of the psychophysiological "cost" of the learning process effectiveness among high-school students. Educational Psychology in a Multicultural Space, 1(21), 47-52.

Nikolaeva, E. I., \& Vergunov, E. G. (2017). Executive functions and their development in ontogenesis. Theoretical and Experimental Psychology, 10(2), 62-81. http://www.tepjournal.ru/en/content/2017/vol-10-2/07 
Paul, T. (2012). How children succeed: grit, curiosity, and the hidden power of character. Houghton Mifflin.

Pfannkuch, M., Budgett, S., Fewster, R., Fitch, M., Pattenwise, S., Wild, C., \& Ziedins, I. (2016). Probability modeling and thinking: What can we learn from practice? Statistics Education Research Journal, 15, 11-37. https://www.learntechlib.org/p/195133/

Polyakova, T. A. (2006). Forming and developing of probabilistic-statistical pupil's consciousness on mathematician's lesson. Omsk Scientific Bulletin, 10(49), 167-169.

Ponomaryov, Y. I., \& Shapovalenko, T. G. (2008). Features of the probabilistic thinking formation among students. Science and School, 3, 20-22.

Razumnikova, O. M. (2019). Age-related features of the ratio of inhibitory functions of the executive attention system and visual memory. Experimental Psychology, 12(2), 6174. https://doi.org/10.17759/exppsy.2019120205

Razumnikova, O. M., \& Savinykh, M. A. (2016). A software package for determining the characteristics of visual-spatial memory systems. Certificate No. 2016617675.

Regush, L. A. (2003). Forecasting psychology. Success in foreknowledge. Speech.

Sari, D. I., \& Hermanto, D. (2017). Development of probabilistic thinking-oriented learning tools for probability materials at junior high school students. AIP Conference Proceedings, 1867(1), 020042. https://doi.org/10.1063/1.4994445

Stepanosova, O. V., Kornilova, T. V., \& Grigorenko, E. L. (2004). Diagnostics of intuition trust. In Proceedings of the 5th International Conference for Young Scientists and Students "Relevant problems of modern science: Social and human sciences. Parts 36-38. Psychology, cultural studies, and art history" (pp. 56-58). Samara State Technical University.

Teplov, B. M. (1961). Individual difference issues. Publishing House of the RSFSR Academy of Pedagogical Sciences.

Theeuwes, J. (2010). Top-down and bottom-up control of visual selection. Acta Psychologica, 123, 77-99. https://doi.org/10.1016/j.actpsy.2010.02.006 